\title{
Asymmetric attention and volatility asymmetry
}

\begin{abstract}
Analyzing a large sample of U.S. firms, we show that the asymmetry of stock return volatility is positively related to investor attention and differences of opinion. Using the number of analysts following a given firm to capture attention and the dispersion in analyst forecasts as a common proxy for differences of opinion, we show that the two effects are complementary. Furthermore, the effect of attention is strongest among stocks with low institutional ownership and high idiosyncratic volatility. Our results are robust to the traditional "leverage effect" explanation of volatility asymmetry. The findings relate to the previously documented relationship between attention and volatility and suggest that volatility asymmetry is driven by asymmetric attention.
\end{abstract}

JEL classification: G11,G12,G14.

Keywords: volatility asymmetry; leverage effect; analysts; investor attention 


\section{Introduction}

When stock prices fall, volatility typically increases - this well-documented volatility asymmetry was initially described as the "leverage effect" (Black 1976, Christie 1982). However, experimental and empirical evidence shows that even assets with zero leverage experience volatility asymmetry (Hens \& Steude 2009, Hasanhodzic \& Lo 2011). While a number of alternative explanations for this effect have been given, it is still "largely unexplained" (Talpsepp \& Rieger 2010), see Bekaert \& Wu (2000) for an overview andJayasuriya, et al. (2009) for further ideas.

We offer a novel explanation based on evidence that attention to the stock market is also asymmetric - investors seem more affected when returns are negative, to the point where hospital admissions spike on days when the market drops (Engelberg \& Parsons 2016). Similarly, Google searches for the phrase "stock market" in the U.S., a natural measure of interest in any topic in the Internet age, are negatively correlated with the return of the S\&P500 index (see Section 2).

The rest of our analysis proceeds by the following logic: since attention is related to volatility, as shown by Andrei \& Hasler (2015), asymmetric attention would naturally give rise to asymmetric volatility. In the cross-section, if investors are generally not paying attention to a firm, then in particular they are not doing so asymmetrically. Hence, firms with an overall higher level of attention should also experience proportionately higher attention asymmetry and thus higher volatility asymmetry. In a large sample of U.S. firms over the 1989 - 2007 period, we find strong support for this mechanism:

First, using analyst coverage as a proxy for the general level of attention to a stock, we find a strong positive relationship with volatility asymmetry. This effect is reinforced when analyst disagree with each other, as captured by the dispersion in their earnings forecasts. Furthermore, attention matters most for stocks with low institutional ownership. This is consistent with the fact that attention effects are most likely to 
matter for less sophisticated, retail investors. In addition, since attention, the way we define it, is a stock-specific characteristic, we expect it to matter most for stocks with high idiosyncratic volatility. Our empirical analysis confirms that. Finally, measures of stock leverage - debt-to-assets ratio and market beta - do not explain our results. Hence, asymmetric attention appears to be an independent and intuitive explanation for volatility asymmetry.

\section{$2 \quad$ Explaining volatility asymmetry}

Volatility asymmetry is a well documented empirical phenomenon (Black 1976, Christie 1982, Schwert 1989). The asymmetry refers to the fact that volatility is higher during periods when returns are negative. It has been found in various settings including equity markets (see e.g. Bekaert \& Wu (2000)), commodities (e.g. Morana (2001)) and currencies (e.g. French, et al. (1987)). The emphasis of the empirical literature has been on the equity markets where the effect is the most profound and the asymmetry is generally found to be larger for the aggregate market index than for individual stocks (Tauchen, et al. 1996, Andersen, et al. 2001).

Our approach to explain this pervasive phenomenon is inspired by the recently documented link between volatility and attention. Andrei \& Hasler (2015) develop a model where, in their own words: "When investors pay little attention to news, information is only gradually incorporated into prices because learning is slow. Therefore, low attention results in low return volatility. In contrast, attentive investors immediately incorporate new information into prices, and thus high attention induces high return volatility." In their model, learning refers to estimating the expected (unobserved) dividend growth rate of a single risky asset. Interestingly, when calibrating the model to US data, they find the attention parameter to be countercyclical, suggesting attention is higher in bad times. ${ }^{1}$

\footnotetext{
${ }^{1}$ A possible explanation for this asymmetry might be loss aversion (Kahneman \& Tversky 1979), since
} 
Do we also see empirical evidence for such "attention asymmetry"? On one hand, people are understandably reluctant to share news of bad investment performance with their peers, as shown by Kaustia \& Knüpfer (2012), but this in itself does not preclude paying (more) attention to bad news. In this spirit, Engelberg \& Parsons (2016) find evidence that investors are significantly affected by negative returns - to the point that hospital admissions spike on days when the stock market falls. Several studies attempt to resolve this question based on the frequency of logins to online investment accounts. Karlsson, et al. (2009) find that retail investors log in less to their online accounts following market declines, consistent with a hedonistic approach that tries to avoid bad news (the "ostrich effect"). Contrasting evidence is presented by Gherzi, et al. (2014), who find login activity to increase in the magnitude of both negative and positive returns (the "meerkat effect"). Perhaps most relevant to the analysis of volatility are the results in Sicherman, et al. (2016). They show that logins overall are positively related to market returns, but logins that result in trades (i.e., those that may actually contribute to volatility) exhibit a negative relationship.

An alternative broader measure of attention is the Search Volume Index (SVI) available from Google Trends, which allows the tracking of the popularity of any search term over time. Its use in the financial context was spearheaded by Da, et al. (2011), who showed that it can predict retail investor trading activity. To illustrate fluctuating attention to the stock market we plot, in Figure 1, the monthly SVI for the term "stock market" for the period from January 2004 to February 2017. We deliberately choose such a simple and generic term to avoid the hindsight bias inherent in more specific keywords and we restrict the geographic location of the searches to the United States. There are several notable spikes in the SVI, which (with the exception of November 2016 - during and after the US presidential election) coincide with periods of negative returns in the US stock market. To formalize the visual intuition, we calculate the correlation between the SVI and the return of the S\&P500 index, which is significantly negative ( $\rho=-0.42$,

it leads people to put more attention on losses than on gains. In this article, however, we do not aim to investigate the psychological reasons behind this asymmetry further. 
$p<0.001)$. We also split all months in this time period into quartiles based on the level of the SVI and find that the average returns in the top quartile (highest attention) are distinctly negative $(-1.35 \%)$, while they are positive in the remaining three quartiles.

We conclude from the above discussion that investor attention, at least the part of it which is related to subsequent trading, increases in times of stock market declines. Given the link between attention and volatility, the asymmetric pattern in attention is a natural candidate to explain volatility asymmetry.

In our analysis, we are careful to take into account previously suggested explanations. Volatility asymmetry was first explained by the leverage effect (Black 1976, Christie 1982) - decreasing stock prices increase the riskiness of equity, corresponding to higher volatility. Later studies (Schwert 1989, Bekaert \& Wu 2000, Figlewski \& Wang 2001, Talpsepp \& Rieger 2010), however, did not find strong relations between the volatility asymmetry and the level of financial leverage. More recently, Daouk \& Ng (2011) show, using a new unlevering approach, that the effect of leverage might have been previously underestimated, while Ericsson, et al. (2016) argue that the effect of leverage accumulates over time. Evidence in Hens \& Steude (2009) and Hasanhodzic \& Lo (2011), however, shows that volatility asymmetry even exists for assets with zero leverage, clearly demonstrating that leverage cannot be the only reason for asymmetric volatility.

The fundamental idea of the leverage explanation has also been criticized on conceptual grounds, since a higher volatility obviously leads to higher risk, but the explanation assumes the reverse causality which is harder to justify.

Due to the deficits of the original explanation, other explanations have been suggested in the past. Most prominent of those is the "volatility feedback" effect, whereby rather than negative returns leading volatility to rise, the causality runs in the opposite direction persistently high volatility depresses returns (Pindyck 1984, Campbell \& Hentschel 1992, Bekaert \& Wu 2000). Other possible explanations include the use of stop-loss orders and portfolio insurance (Sentana \& Wadhwani 1992). 
There is also a growing number of studies that propose behavioral explanations (Shefrin 2005, Avramov, et al. 2006, Hens \& Steude 2009, Talpsepp \& Rieger 2010, Dzielinski, et al. 2011). Avramov et al. (2006) show that herding can have effects on volatility asymmetry. Talpsepp \& Rieger (2010) find that the level of economic development and market efficiency are (inversely) related to volatility asymmetry after studying stock market indexes of 49 countries. They also find that the volatility asymmetry is positively related to analyst coverage and media penetration. This finding is further discussed by Dzielinski et al. (2011) who also point out that the number of individual investors in the market can have an effect on volatility asymmetry.

\section{Numerical measurement of volatility asymmetry}

We use daily stock returns from the Center for Research in Security Prices (CRSP) to generate monthly estimates of volatility asymmetry for a broad sample of US stocks. To enter the sample, a stock needs to have at least 12 months of returns and at least one year of accounting data available, so that we can calculate (and later control for) known cross-sectional predictors of stock returns, Size, Book-to-Market and Momentum, since these could affect volatility asymmetry as well. Conditional on the availability of these variables, our estimation sample consists of over 16.5 million observations for 7,133 US stocks over the period 1989-2007.

There are a number of possible methods to measure volatility asymmetry. While earlier papers relied on variance modelling, the next generation of literature shifted towards the use of various GARCH type models (for an overview see Bekaert \& Wu (2000)) and with the availability of intraday tick data, some studies focused on realized volatility calculated from intraday data (e.g. Andersen et al. (2001)). Indeed, (Bollerslev, et al. 2006) show that using realized volatility with intraday data slightly improves the accuracy of volatility asymmetry estimates but the results obtained with intraday data are generally in line with volatility asymmetry estimates obtained with daily data. Thus, and espe- 
cially for longer time horizons and large cross-sections, using daily data and GARCH type models is still the main method of choice. There is a number of GARCH type models available that incorporate volatility asymmetry in the original setup that can be used for the task (see Poon \& Granger (2003) for an overview on different models). Some studies also utilize Markov Chain Monte Carlo methods for volatility modeling to capture the asymmetry (Selçuk 2005, Du, et al. 2011).

We use the asymmetric power GARCH (APARCH) model introduced by (Ding, et al. 1993) to estimate the magnitude of volatility asymmetry following the methodology of (Talpsepp \& Rieger 2010). We use a skewed $t$-distribution and a kernel weighting function for the model inputs. As argued by (Talpsepp \& Rieger 2010) this makes it possible to estimate model parameters (including volatility asymmetry) with relatively low standard errors and allows us to use rather short time periods for the estimation procedure.

We use the APARCH$(1,1)$ model without constants and ARMA orders. We do not impose any restrictions on the skewness or kurtosis of the distribution and the shape of the distribution is to be determined by the data. The model is given as:

$$
\begin{aligned}
y_{t} & =x_{1, t}^{\prime} \mu+\varepsilon_{t}, \\
\varepsilon_{t} & =\sigma_{t} z_{t}, \\
\sigma_{t}^{\delta} & =a_{1}\left(\left|\varepsilon_{t-1}\right|-\gamma \varepsilon_{t-1}\right)^{\delta}+\beta_{1} \sigma_{t-1}^{\delta},
\end{aligned}
$$

where $x_{1, t}$ is a vector of weakly exogenous variables, $\mu, a_{1}, \gamma, \beta_{1}$ and $\delta$ are parameters to be estimated, $\varepsilon_{t}$ is the residual term and $z_{t}$ is a standard random variable that follows Student's distribution. The parameter $\delta$ plays the role of a Box-Cox transformation of the conditional standard deviation $\sigma_{t}$, and $\gamma$ reflects the volatility asymmetry. A positive value of $\gamma$ means that volatility is larger when return innovations are negative. 
We use a moving time window for observations to estimate the volatility asymmetry for every stock in our sample. This means that we run the model estimation (initially for period $\left.t_{0} \ldots t_{1000}\right)$ to obtain an estimate of the asymmetry parameter $\gamma$ and then repeat the procedure with a step of 5 observations (i.e. running the model for period $t_{5} \ldots t_{1005}$ etc.). Thus, we use the rolling time window estimation of the APARCH model to obtain in principle one estimate of the asymmetry parameter $\gamma$ per week, which we then average to monthly frequency. This allows us to build a time series of volatility asymmetry estimates for every stock in our sample.

Following the methodology of Talpsepp \& Rieger (2010), we eliminate outliers from the time series of the stock returns. We use a wavelet-based outlier detection method (Fan \& Wang 2007) along with a method which is based on local volatility comparison (Lee \& Mykland 2008) to identify outliers in the returns. Running APARCH type models poses certain problems when the return series contains jumps as maximum likelihood estimations may not converge. As discussed by Talpsepp \& Rieger (2010), eliminating outliers does not qualitatively change the results and the number of detected and eliminated outliers remains less than $2 \%$ of all observations.

The total number of estimations run for our sample is very large since we use a moving time window for the APARCH model estimation and have to run the model many times for every stock in the sample. As stated, APARCH model estimations use the maximum likelihood estimation which once again means a large number of iterations to obtain the parameter estimates. That means a heavy computational load which translates to approximately 4-5 months of continuous computational time with one standard (4 core $\mathrm{CPU}$ ) computer for getting the necessary estimates of the volatility asymmetry parameters for our sample of stocks.

Figure 2 presents the distribution of the 791,467 monthly asymmetry parameter $(\gamma)$ estimates that we obtain across all stocks in the sample. A clear majority of them (around $86 \%$ ) are positive, consistent with a pervasive volatility asymmetry effect. However, 
there is substantial heterogeneity in the estimates, suggesting that some stocks feature much stronger asymmetry than others. Explaining this heterogeneity is the main focus of our empirical analysis.

\section{Empirical results}

Our first hypothesis states that stocks with a higher level of attention should experience more pronounced volatility asymmetry. To proxy for attention at the stock level, we rely on analyst coverage. Kelly \& Ljungqvist (2012) show that analysts are important sources of information, although they can also be biased (usually too optimistic), due to e.g. career concerns (Hong \& Kubik 2003). The key aspect for us is that investors are likely to pay more attention to firms covered by more analysts, also because analyst coverage is correlated with other aspects of a firm's visibility, such as media coverage and size. More formally, suppose that $s$, the level of attention to a particular company, is a concave function of the number of analysts, $n$ (the implicit assumption of decreasing marginal attention seems natural). To have a concrete example, assume

$$
s=n^{p}, \text { where } p \in(0,1) .
$$

To introduce asymmetric attention, we assume $p_{\text {pos }}<p_{\text {neg }}$, so that attention to a negative signal is always higher than to a positive one, for all $n>1 .^{2}$ It follows that the asymmetry of attention is given by:

$$
\frac{s_{\text {neg }}}{s_{\text {pos }}}=n^{p_{\text {neg }}-p_{\text {pos }}}
$$

which is an increasing function of $n$.

\footnotetext{
${ }^{2}$ Other specifications are possible. Indeed, one can show that it is sufficient to assume that the concavity is stronger in positive than in negative news, i.e. $s_{\text {pos }}^{\prime \prime}<s_{\text {neg }}^{\prime \prime}$.
} 
It is important to note that we are not trying to capture attention specifically to analyst signals (such as recommendations) but rather towards the company more generally. ${ }^{3}$ To illustrate our thinking, consider a company such as General Electric, which in our sample is followed by more than 20 analysts on average, versus a small and relatively unknown company with little or no coverage. Bad news about the small company may still be noticed by some investors but bad news about GE is likely to generate a lot more attention. On the other hand, if good news is generally less attention-grabbing, it may go relatively unnoticed for both GE and the small company. In this way, the level of attention should go hand in hand with attention asymmetry and relate to volatility asymmetry as well (indeed, GE's average coefficient of volatility asymmetry is around the 90th percentile of the sample distribution).

We measure coverage as the number of analysts with active earnings forecasts for a given stock, as reported every month in the Institutional Brokers' Estimate System (IBES). We merge monthly volatility asymmetry estimates to monthly analyst coverage statistics. We find that of the 7,133 stocks in our sample, 5,206 are covered by at least one analyst and 4,589 by at least two analysts, which additionally allows us to examine the dispersion of their forecasts. We expect forecast dispersion to reinforce the effect of analyst coverage on volatility asymmetry, based on the following intuition. Stocks with greater analyst coverage attract more investor attention, especially in bad times (asymmetric attention). If in addition to paying more attention, investors are also faced with more conflicted information (higher forecast dispersion), they are more likely to disagree with each other. ${ }^{4}$ This will further increase volatility, especially in bad times. Hence, we expect the number and dispersion of analyst forecasts to have a positive interaction effect on volatility asymmetry.

Table 1 presents summary statistics of our sample. The mean volatility asymmetry

\footnotetext{
${ }^{3}$ If one were interested in asymmetric attention to analyst signals specifically, then a measure such as the number of downgrades or the proportion of downgrades to upgrades could be more suitable.

${ }^{4}$ Forecast dispersion has been used to proxy for differences of opinions in numerous studies, beginning with (Diether, et al. 2002).
} 
estimate is 0.176 with a relatively large standard deviation, confirming the heterogeneity across stocks.

[Insert Table 1 approximately here]

The average stock in our sample is followed by close to 5 analysts every month but coverage is considerably skewed and to mitigate this problem we use logs in subsequent estimations. To be able to include stocks with zero analyst estimates, we define our coverage variable for stock $i$ in month $t$ as

$$
\log N u m E s t_{i, t}=\log \left(1+N u m E s t_{i, t}\right)
$$

Forecast dispersion, AnalyDisp, is defined as the standard deviations of analyst forecasts for stock $i$ in month $t$, scaled by the mean forecast. We trim it at the 99th percentile, to limit large outliers due to scaling when the mean forecast is very close to zero.

We provide preliminary evidence for our main hypothesis in Figure 3 where we plot the average asymmetry coefficient $\gamma$ for groups of stocks sorted on analyst coverage. We use tercile breakpoints and include stocks with no analyst coverage as a separate category. There is a clear separation between the terciles and the average $\gamma$ in the 'High' tercile is often twice as large as in the 'Low' one. Interestingly, there is little difference between stocks with low coverage and no coverage at all, suggesting that the effect comes mostly from the intensity, rather than mere existence, of coverage. Finally, there is some comevement across terciles suggesting common drivers of volatility asymmetry over time.

To account for such time trends and common aggregate shocks to volatility asymmetry, we include year-month fixed effects in all our regressions. Given our moving-window approach to estimating volatility asymmetry, the resulting $\gamma$ estimates are not independent over time. Hence, in the regressions that follow, we include stock fixed effects and cluster standard errors by stock. The baseline regression we estimate is: 


$$
\gamma_{i, t+1}=\left[\beta_{1}, \beta_{2} \cdot\right] \cdot\left[\begin{array}{c}
\log N u m E s t_{i, t} \\
\text { AnalyDisp } p_{i, t}
\end{array}\right]+\beta_{k} \cdot \text { Controls }_{i, t}^{k}+\alpha_{i}+\delta_{t}+\epsilon_{i, t}
$$

where $\alpha_{i}$ and $\delta_{t}$ are the stock and year-month fixed effects respectively and the Controls matrix contains Size, Book-to-Market and Momentum variables for each stock-month. ${ }^{5}$

Table 2 contains our main results. First, in column (1), we show that analyst coverage is a significant driver of volatility asymmetry. The estimated coefficient on $\operatorname{logNumEst}$ is positive and highly significant $(t=6.37)$. The economic magnitude is also substantial: a one-standard deviation increase in logNumEst leads to an increase in the coefficient of volatility asymmetry by $0.016(1.09 \times 0.015)$, or $9.3 \%$ relative to its unconditional mean of 0.176 .

[Insert Table 2 approximately here]

To disentangle the intensity from the existence of coverage we consider two additional specifications. In column (2) we run the regression using only stocks covered by at least one analyst in a given month and obtain similar results. Alternatively, in column (3), we use all stocks but include, alongside $\log N u m E s t$, an indicator variable, CovDummy, which takes the value of 1 if a stock was followed by at least one analyst in a given month and 0 otherwise. The coefficient on the coverage dummy is positive and statistically significant - volatility asymmetry among covered stocks is on average $7.4 \%(1 \times 0.013 / 0.176)$ higher than for non-covered ones. However, even though the magnitude of the coefficient on $\log N u m E s t$ drops to 0.009 , it remains highly statistically significant. This suggests that volatility asymmetry is related to the quantity and not just the mere existence of coverage, in line with our main hypothesis.

Finally, we explore the role of forecast dispersion, which limits our sample to stocks

\footnotetext{
${ }^{5}$ We calculate Book-to-Market ratio of each stock every year in June, following (Fama \& French 1993), and use that value for the following 12 months.
} 
covered by at least two analysts. First, in column (4), we find that both logNumEst and AnalyDisp are significantly and positively related to volatility asymmetry when included alongside each other. More importantly, we show in column (5) that the interaction of these two variables is also positive and significant. This confirms our expectations that higher attention coupled with more conflicted signals is a particularly explosive combination for exacerbating volatility in bad times.

\subsection{Where does asymmetric attention matter most?}

We refine our main hypothesis by looking at subsamples of stocks, in which we might expect attention effects to differ. First, professional institutional investors are less likely to exhibit the asymmetric attention patterns documented in Google searches. Second, analyst coverage is by construction a measure of stock-specific attention. Hence, we would expect it to matter more among stocks, for which volatility is also largely stockspecific (idiosyncratic) as well as those with relatively low institutional ownership.

We define institutional ownership as the fraction of shares outstanding held by investors filing Form 13-f, which we obtain from Thomson Reuters. This data is available quarterly, so we use the same value for the three months following the end of every quarter. We calculate idiosyncratic volatility as the sum of squared residuals from a Fama-French three-factor model, estimated every month for each stock using daily returns. Finally, we group stocks into terciles of institutional ownership and idiosyncratic volatility and estimate our baseline regression in the bottom and top tercile separately.

[Insert Table 3 approximately here]

Results presented in Table 3 are consistent with our argument. The coefficient on $\log N u m E s t$ is twice as large among stocks with low institutional ownership and its statistical significance is much higher. On the other hand, stocks with low idiosyncratic volatility feature a much weaker link between stock-specific attention and volatility asym- 
metry. However, it is worth noting the $\log N u m E s t$ remains significant in all subsamples, as does AnalyDisp.

\subsection{Is it just leverage?}

In this section we discuss our main findings in the context of the original leverage-based explanation of volatility asymmetry. We define leverage in two ways. The first one is based on capital structure and relates the amount of debt to the combined amount of debt and equity. The other approach is based on market beta, which can be interpreted as the leverage of the stock's return relative to the market return. According to the standard "leverage effect", both variables should be positively related to volatility asymmetry. We estimate our baseline regression in terciles formed on debt-to-assets and market beta. Results from the bottom and top terciles are presented in Table 4.

[Insert Table 4 approximately here]

The coefficient on $\log N u m E s t$ is statistically significant among stocks with both low and high ratios of debt. Its magnitude is very similar to the full sample, suggesting that debt-to-assets and attention are not significantly correlated. On the other hand, we do see a difference across terciles of market beta. The coefficient on $\log N u m E s t$ is large and significant among low-beta stocks but is not significant among high-beta stocks. This does not mean that market beta subsumes the effect of attention, because then we would not see any effect of $\log N u m E s t$ in either of the terciles. Finally, AnalyDisp remains significant across all the subsamples. Taken together, these results give us confidence that attention and conflicting information are important drivers of volatility asymmetry, largely independent of the traditional "leverage effect". 


\section{Conclusions}

In this article we have proposed that asymmetry in the attention to good and bad news can lead to volatility asymmetry, i.e. increased volatility following declines of the stock price. The suggested asymmetry of attention to news can be seen in the negative correlation between the Google Search Volume Index for the phrase "stock market" and actual stock market returns. We develop and subsequently confirm 3 predictions regarding the effect of asymmetric attention on volatility asymmetry:

- Stocks that have in general a higher level of attention as proxied by the number of analysts giving forecasts for them, also show a larger volatility asymmetry.

- Attention to a stock and the dispersion of information about it (analyst earnings forecast) jointly increase volatility asymmetry.

- Stocks with low institutional ownership (i.e. a larger proportion of retail investors that are more prone to attention effects) also show a larger volatility asymmetry.

Given that high volatility is considered problematic and regulators aim to reduce it, it might be interesting to discuss how regulations of stock market may affect volatility given our proposed relation between attention to news and volatility asymmetry. This is especially important, since high amounts of volatility are considered to be particularly disadvantageous in declining markets - an issue that results directly from volatility asymmetry.

\section{References}

T. Andersen, et al. (2001). 'The distribution of realized stock return volatility'. Journal of Financial Economics 61(1):43-76. 
D. Andrei \& M. Hasler (2015). 'Investor attention and stock market volatility'. Review of Financial Studies 28(1):33-72.

D. Avramov, et al. (2006). 'The impact of trades on daily volatility'. Review of Financial Studies 19(4):1241-1277.

G. Bekaert \& G. Wu (2000). 'Asymmetric volatility and risk in equity markets'. Review of Financial Studies 13(1):1-42.

F. Black (1976). 'Studies of stock price volatility changes'. Proceedings of the 1976 Meetings of the Business and Economic Statistics Section, American Statistical Association pp. $177-181$.

T. Bollerslev, et al. (2006). 'Leverage and volatility feedback effects in high-frequency data'. Journal of Financial Econometrics 4(3):353-384.

J. Campbell \& L. Hentschel (1992). 'No News is Good News: An Asymmetric Model of Changing Volatility in Stock Returns'. Journal of Financial Economics 31:281-318.

A. Christie (1982). 'The Stochastic Behavior of Common Stock Variances: Value, Leverage and Interest Rate Effects'. Journal of Financial Economics 10(4):407-432.

Z. Da, et al. (2011). 'In Search of Attention'. Journal of Finance 66(5):1461-1499.

H. Daouk \& D. Ng (2011). 'Is unlevered firm volatility asymmetric?'. Journal of Empirical Finance 18(4):634-651.

K. Diether, et al. (2002). 'Differences of opinion and the cross section of stock returns'. The Journal of Finance (October 2002):2113-2141.

Z. Ding, et al. (1993). 'A long memory property of stock market returns and a new model'. Journal of Empirical Finance 1(1):83-106.

X. Du, et al. (2011). 'Speculation and volatility spillover in the crude oil and agricultural commodity markets: A Bayesian analysis'. Energy Economics 33(3):497-503. 
M. Dzielinski, et al. (2011). 'Volatility asymmetry, news, and private investors'. The Handbook of News Analytics in Finance pp. 255-270.

J. Engelberg \& C. A. Parsons (2016). 'Worrying about the Stock Market: Evidence from Hospital Admissions'. Journal of Finance 71(3):1227-1250.

J. Ericsson, et al. (2016). 'Leverage and asymmetric volatility: The firm-level evidence'. Journal of Empirical Finance 38:1-21.

E. F. Fama \& K. R. French (1993). 'Common risk factors in the returns on stocks and bonds'. Journal of Financial Economics 33:3-56.

J. Fan \& Y. Wang (2007). 'Multi-Scale Jump and Volatility Analysis for High-Frequency Financial Data'. Journal of the American Statistical Association 102(480):1349-1362.

S. Figlewski \& X. Wang (2001). 'Is the'Leverage Effect'a Leverage Effect?'. Mimeo, New York University .

K. French, et al. (1987). 'Expected stock returns and volatility'. Journal of Financial Economics 19(1):3-29.

S. Gherzi, et al. (2014). 'The meerkat effect: Personality and market returns affect investors' portfolio monitoring behaviour'. Journal of Economic Behavior and Organization 107(PB):512-526.

J. Hasanhodzic \& A. Lo (2011). 'Black's Leverage Effect is not due to Leverage'. SSRN Electronic Journal 1971(646).

T. Hens \& S. Steude (2009). 'The Leverage Effect without Leverage: An Experimental Study'. Finance Research Letters 6(2):83-94.

H. Hong \& J. D. Kubik (2003). 'Analyzing the Analysts: Career Concerns and Biased Earnings Forecasts'. Journal of Finance 58(1):313-351.

S. Jayasuriya, et al. (2009). 'Asymmetric volatility in emerging and mature markets'. Journal of Emerging Market Finance 8(1):25-43. 
D. Kahneman \& A. Tversky (1979). 'Prospect Theory: An Analysis of Decision Under Risk'. Econometrica 47:263-291.

N. Karlsson, et al. (2009). "The "Ostrich Effect": Selective Attention to Information about Investments'. Journal of Risk and Uncertainty 38:95-115.

M. Kaustia \& S. Knüpfer (2012). 'Peer performance and stock market entry'. Journal of Financial Economics 104(2):321-338.

B. Kelly \& A. Ljungqvist (2012). 'Testing asymmetric-information asset pricing models'. Review of Financial Studies 25(5):1366-1413.

S. S. Lee \& P. A. Mykland (2008). 'Jumps in financial markets: A new nonparametric test and jump dynamics'. Review of Financial studies 21(6):2535-2563.

C. Morana (2001). 'A semiparametric approach to short-term oil price forecasting'. Energy Economics 23(3):325-338.

R. S. Pindyck (1984). 'Risk, Inflation, and the Stock Market'. American Economic Review 74(3):335-51.

S. Poon \& C. Granger (2003). 'Forecasting Volatility in Financial Markets: A Review'. Journal of Economic Literature 41(2):478-539.

M. Scholes \& J. Williams (1977). 'Estimating betas from nonsynchronous data'. Journal of Financial Economics 5(3):309-327.

G. Schwert (1989). 'Why Does Stock Market Volatility Change Over Time?'. The Journal of Finance 44(5):1115-1153.

F. Selçuk (2005). 'Asymmetric stochastic volatility in emerging stock markets'. Applied Financial Economics 15(12):867-874.

E. Sentana \& S. Wadhwani (1992). 'Feedback Traders and Stock Return Autocorrelations: Evidence from a Century of Daily Data'. The Economic Journal 102(411):415425 . 
H. Shefrin (2005). A Behavioral Approach to Asset Pricing. Elsevier.

N. Sicherman, et al. (2016). 'Financial Attention'. Review of Financial Studies 29(4):863-897.

T. Talpsepp \& M. O. Rieger (2010). 'Explaining asymmetric volatility around the world'. Journal of Empirical Finance 17(5):938-956.

G. Tauchen, et al. (1996). 'Volume, volatility, and leverage: A dynamic analysis'. Journal of Econometrics 74(1):177-208. 
Figure 1: Google Trends and asymmetric attention to the stock market

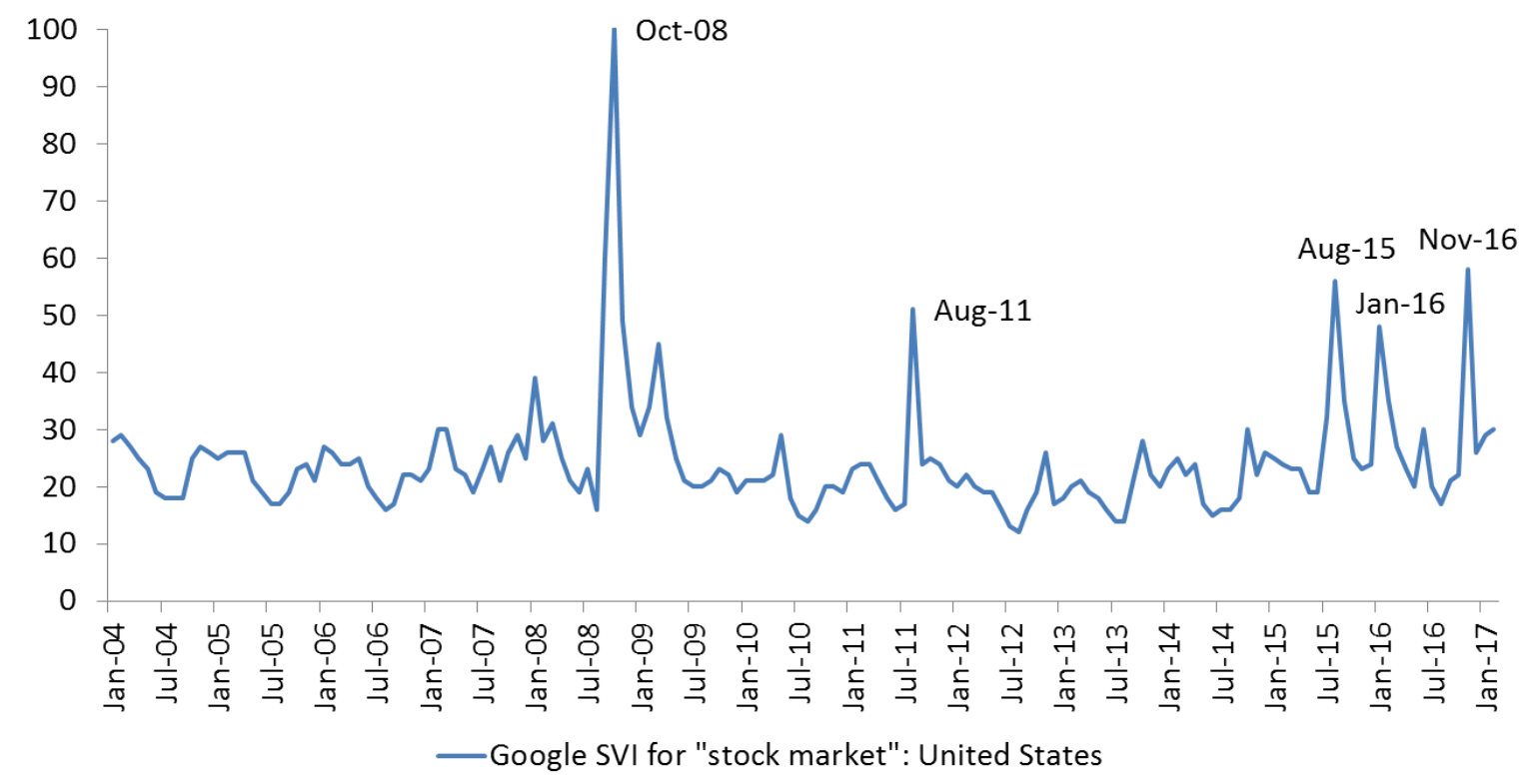

The source of the Search Volume Index (SVI) is Google Trends, which makes it possible to track the popularity of arbitrary keywords, the phrase "stock market" in this case, in the Google search engine. The geographic location of searches is restricted to the United States and the period is Jan 2004 to Feb 2017. Google Trends automatically scales the values of the SVI relative to the maximum over the sample period, which is set to 100 . 
Figure 2: Distribution of volatility asymmetry estimates

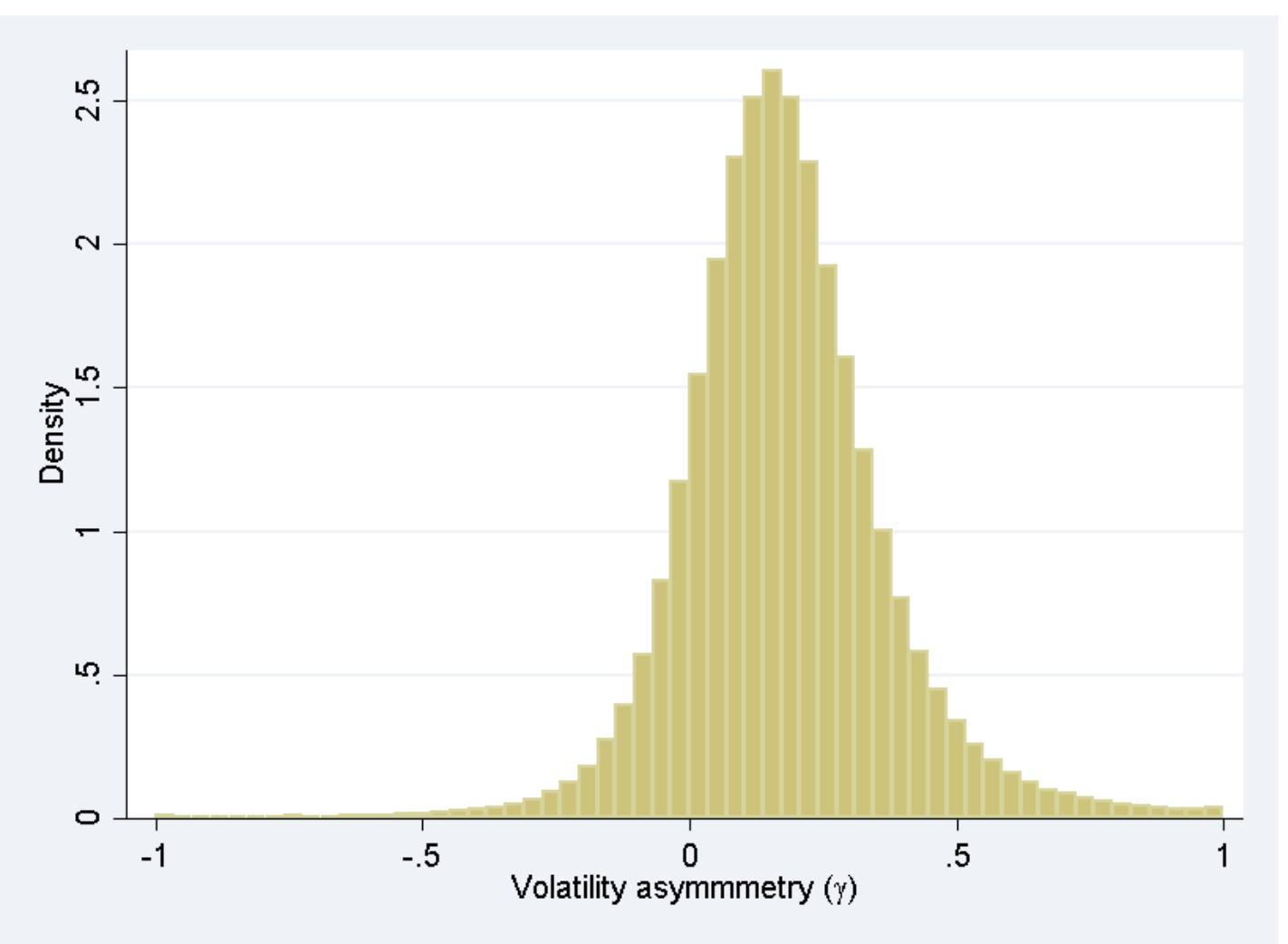

The figure shows a histogram of monthly volatility asymmetry estimates $\gamma$, obtained from the APARCH $(1,1)$ model described in section 3, for the cross-section of US stocks. Positive values of $\gamma$ mean that volatility is higher when stock returns are negative. 
Figure 3: Volatility asymmetry over time, sorted on number of analysts' estimates

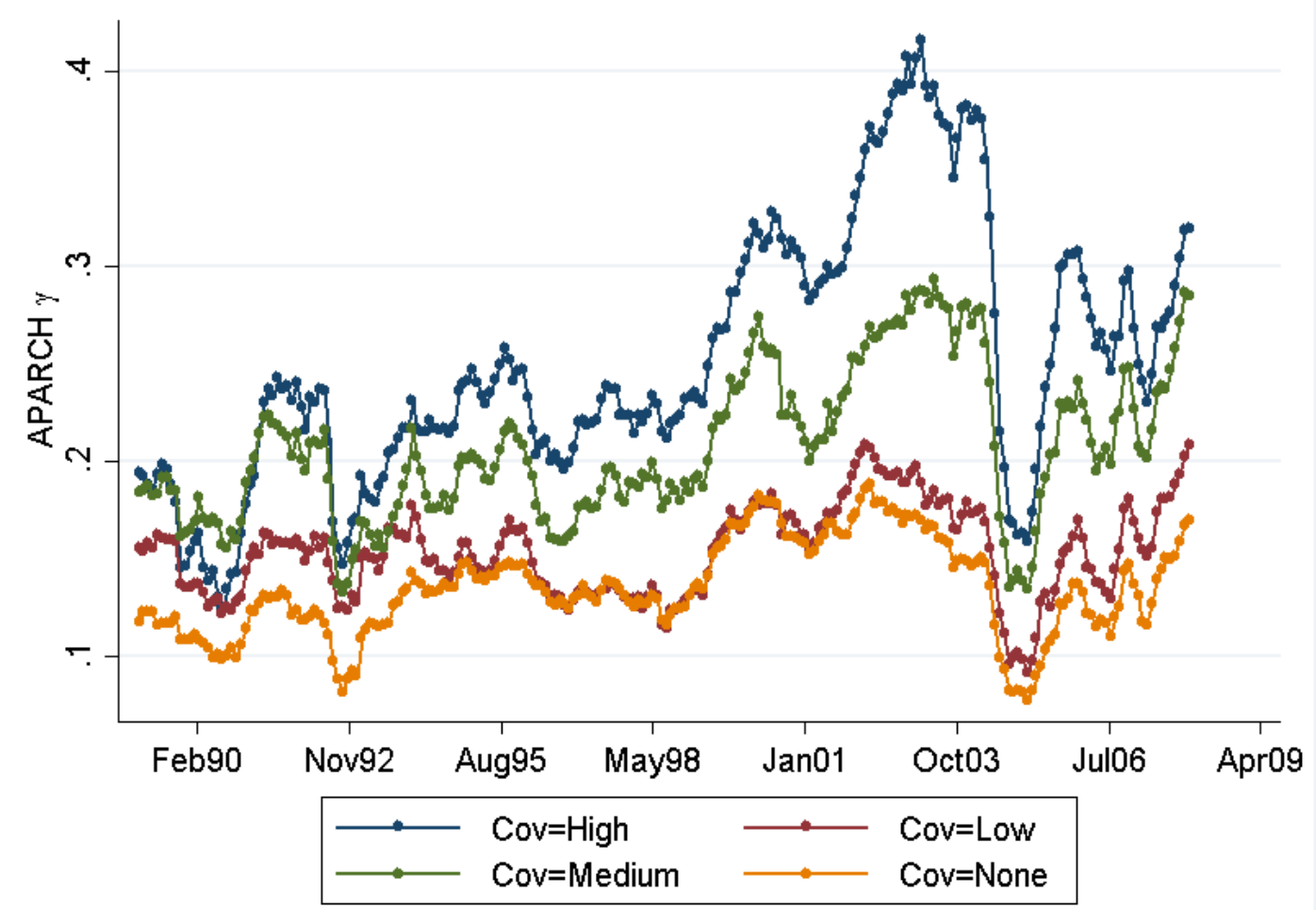

In this figure, all stocks are divided each month into terciles of analyst coverage, as measured by the number of earnings forecasts recorded by IBES, and the average volatility asymmetry coefficient (APARCH $\gamma$ is calculated within each tercile. We also construct an additional category to accommodate stocks with no analyst coverage. 
Table 1: Summary statistics

\begin{tabular}{|c|c|c|c|c|c|c|c|c|}
\hline & $\mathrm{N}$ & Mean & StDev & p1 & p10 & $\mathrm{p} 50$ & p90 & p99 \\
\hline APARCH $\gamma$ & 791,453 & 0.176 & 0.197 & -0.324 & -0.0329 & 0.167 & 0.403 & 0.765 \\
\hline NumEst & 791,453 & 4.632 & 6.845 & 0 & 0 & 2 & 14 & 30 \\
\hline AnalyError & 474,892 & 0.159 & 1.733 & -1.576 & -0.179 & 0.0163 & 0.664 & 4.071 \\
\hline AnalyDisp & 399,090 & 0.105 & 0.214 & 0 & 0.00847 & 0.0370 & 0.235 & 1.235 \\
\hline InstOwn & 776,648 & 0.382 & 0.269 & 0.00198 & 0.0444 & 0.351 & 0.769 & 0.959 \\
\hline IdiosVol & 791,447 & 0.0278 & 0.0229 & 0.00510 & 0.00920 & 0.0214 & 0.0531 & 0.111 \\
\hline Debt-to-Assets & 770,665 & 0.251 & 0.241 & 0 & 0 & 0.185 & 0.619 & 0.879 \\
\hline Beta & 786,601 & 0.746 & 0.631 & -0.467 & 0.0321 & 0.671 & 1.576 & 2.536 \\
\hline Size & 791,453 & 5.343 & 2.068 & 1.330 & 2.760 & 5.195 & 8.114 & 10.53 \\
\hline Book-to-Market & 791,453 & 0.769 & 0.957 & 0.0457 & 0.187 & 0.594 & 1.416 & 3.512 \\
\hline Momentum & 791,453 & 0.213 & 0.825 & -0.758 & -0.400 & 0.0911 & 0.814 & 3.084 \\
\hline
\end{tabular}

This table summarizes the variables in our analysis. We use monthly observations for 7,133 US stocks between 1989 and 2007. APARCH $\gamma$ is the measure of volatility asymmetry developed in Section 3. NumEst is the number of analysts following the stock in a given month according to IBES. AnalyError is calculated as the difference between the consensus estimate of next quarter's earnings and subsequent actually announced earnings, scaled by the consensus estimate. AnalyDisp is the standard deviation of analyst estimates of next quarter's earnings, scaled by the consensus estimate. InstOwn is the fraction of shares outstanding held by investors filing Form 13-f. IdiosVol is the sum of squared residuals from a Fama-French three-factor model estimated for each stock every month using daily returns. Debt - to - Assets is defined as debt (long term + debt in current liabilities) divided by the sum of debt and market value of equity. We obtain annual market Beta of each stock, estimated at the end of each year following Scholes \& Williams (1977), from CRSP. Size is the log of market capitalization at the end of each month. Book-to-Market $(B t M)$ is the ratio of book value of equity to its market value, estimated at the end of June each year, as in Fama \& French (1993). Momentum is the cumulative return over the previous 12 months, skipping the most recent month. 
Table 2: Volatility asymmetry, analyst coverage and forecast dispersion

\begin{tabular}{|c|c|c|c|c|c|}
\hline & \multirow{2}{*}{$\begin{array}{l}\text { All stocks } \\
\text { (1) }\end{array}$} & \multirow{2}{*}{$\begin{array}{l}\text { Excluding stocks } \\
\text { with no analysts } \\
\text { (2) }\end{array}$} & \multirow{2}{*}{$\begin{array}{c}\text { Including } \\
\text { coverage dummy } \\
\text { (3) }\end{array}$} & \multicolumn{2}{|c|}{$\begin{array}{c}\text { Stocks with at least } \\
\text { two analysts }\end{array}$} \\
\hline & & & & (4) & (5) \\
\hline \multirow[t]{2}{*}{ logNumEst } & $0.015^{* * *}$ & $0.018^{* * *}$ & $0.009 * * *$ & $0.018^{* * *}$ & $0.016^{* * *}$ \\
\hline & $(6.37)$ & $(5.24)$ & $(2.97)$ & $(4.25)$ & $(3.84)$ \\
\hline \multirow[t]{2}{*}{ AnalyDisp } & & & & $0.012^{* * *}$ & -0.009 \\
\hline & & & & $(3.70)$ & $(-0.91)$ \\
\hline $\operatorname{logNumEst}$ & & & & & $0.012^{* *}$ \\
\hline$\times$ AnalyDisp & & & & & $(2.02)$ \\
\hline \multirow[t]{2}{*}{ CovDummy } & & & $0.013^{* * *}$ & & \\
\hline & & & $(3.14)$ & & \\
\hline \multirow[t]{2}{*}{ Size } & 0.000 & $-0.011^{* * *}$ & 0.001 & $-0.014^{* * *}$ & $-0.013^{* * *}$ \\
\hline & $(0.11)$ & $(-4.34)$ & $(0.33)$ & $(-4.85)$ & $(-4.80)$ \\
\hline \multirow[t]{2}{*}{ Book-to-Market } & $-0.002^{* *}$ & $-0.005^{* * *}$ & $-0.002^{* *}$ & $-0.005^{* * *}$ & $-0.005^{* * *}$ \\
\hline & $(-2.31)$ & $(-2.84)$ & $(-2.20)$ & $(-2.77)$ & $(-2.76)$ \\
\hline \multirow[t]{2}{*}{ Momentum } & $-0.013^{* * *}$ & $-0.012^{* * *}$ & $-0.013^{* * *}$ & $-0.012^{* * *}$ & $-0.012^{* * *}$ \\
\hline & $(-14.26)$ & $(-10.79)$ & $(-14.33)$ & $(-9.35)$ & $(-9.35)$ \\
\hline \multirow[t]{2}{*}{ Intercept } & $0.133^{* * *}$ & $0.193^{* * *}$ & $0.130^{* * *}$ & $0.216^{* * *}$ & $0.218^{* * *}$ \\
\hline & $(15.97)$ & $(16.38)$ & $(15.41)$ & $(14.95)$ & $(15.05)$ \\
\hline Nobs & 791,453 & 484,555 & 791,453 & 399,090 & 399,090 \\
\hline Year-month f.e. & YES & YES & YES & YES & YES \\
\hline Firm f.e. & YES & YES & YES & YES & YES \\
\hline $\mathrm{R}^{2}$ & 0.382 & 0.375 & 0.382 & 0.371 & 0.371 \\
\hline Nfirms & 7133 & 5206 & 7133 & 4589 & 4589 \\
\hline
\end{tabular}

The dependent variable in all regressions is monthly $A P A R C H \gamma$, our measure of volatility asymmetry developed in Section 3. Our main explanatory variable, $\log N u m E s t$, is the natural logarithm of the number of analysts following the stock in a given month according to IBES and proxies for the level of attention toward each stock. AnalyDisp is the dispersion of analyst forecasts of next quarter's earnings and is a common measure for differences of opinion. All variables are defined in Table 1. Monthly observations between 1989 and 2007 are used. $t$-statistics are calculated from standard errors clustered by stock. Significance levels: * $-0.1,{ }^{* *}-0.05,{ }^{* * *}-0.01$ 
Table 3: Volatility asymmetry - where is the effect the strongest?

\begin{tabular}{|c|c|c|c|c|}
\hline & \multicolumn{2}{|c|}{ Sorted on institutional ownership } & \multicolumn{2}{|c|}{ Sorted on idiosyncratic volatility } \\
\hline & Low & High & Low & High \\
\hline & (1) & $(2)$ & $(3)$ & $(4)$ \\
\hline \multirow[t]{2}{*}{ logNumEst } & $0.034^{* * *}$ & $0.015^{*}$ & $0.015^{* *}$ & $0.023^{* * *}$ \\
\hline & $(5.40)$ & $(1.84)$ & $(2.31)$ & $(4.81)$ \\
\hline \multirow[t]{2}{*}{ AnalyDisp } & $0.010^{* * *}$ & $0.020 * *$ & $0.032^{* * *}$ & $0.007^{* *}$ \\
\hline & $(2.63)$ & $(2.39)$ & $(2.65)$ & $(2.29)$ \\
\hline \multirow[t]{2}{*}{ Size } & $-0.016^{* * *}$ & $-0.020 * * *$ & 0.001 & $-0.019 * * *$ \\
\hline & $(-3.80)$ & $(-4.19)$ & $(0.19)$ & $(-7.36)$ \\
\hline \multirow[t]{2}{*}{ Book-to-Market } & $-0.006^{*}$ & $-0.007 * *$ & 0.003 & $-0.005^{* *}$ \\
\hline & $(-1.86)$ & $(-2.35)$ & $(1.26)$ & $(-2.38)$ \\
\hline \multirow[t]{2}{*}{ Momentum } & $-0.009^{* * *}$ & $-0.013^{* * *}$ & $-0.054^{* * *}$ & $-0.005^{* * *}$ \\
\hline & $(-4.89)$ & $(-5.38)$ & $(-12.32)$ & $(-4.86)$ \\
\hline \multirow[t]{2}{*}{ Intercept } & $0.173^{* * *}$ & $0.294^{* * *}$ & $0.104^{* * *}$ & $0.261^{* * *}$ \\
\hline & $(8.05)$ & $(10.47)$ & $(3.28)$ & (19.16) \\
\hline Nobs & 133,042 & 132,896 & 133,102 & 132,961 \\
\hline Year-month f.e. & YES & YES & YES & YES \\
\hline Firm f.e. & YES & YES & YES & YES \\
\hline $\mathrm{R}^{2}$ & 0.443 & 0.377 & 0.404 & 0.418 \\
\hline Nfirms & 3437 & 2195 & 3501 & 4364 \\
\hline
\end{tabular}

The dependent variable in all regressions is monthly $A P A R C H \gamma$, our measure of volatility asymmetry developed in Section 3. Our main explanatory variable, $\log N u m E s t$, is the natural logarithm of the number of analysts following the stock in a given month according to IBES and proxies for the level of attention toward each stock. AnalyDisp is the dispersion of analyst forecasts of next quarter's earnings and is a common measure for differences of opinion. In columns (1) and (2), we sort stocks into terciles of institutional ownership (InstOwn), which is the fraction of shares outstanding held by investors filing Form 13-f in a given quarter. In columns (3) and (4), we sort stocks into terciles of idiosyncratic volatility $($ Idios $V o l)$, which is the sum of squared residuals from estimating a Fama-French three-factor model for each stock every month using daily returns. We then run regressions following Equation 6 in the bottom and top tercile separately and present the results. All variables are defined in Table 1. Monthly observations between 1989 and 2007 are used. $t$-statistics are calculated from standard errors clustered by stock.

Significance levels: * $-0.1, * *-0.05, * * *-0.01$ 
Table 4: Volatility asymmetry - comparison with leverage explanations

\begin{tabular}{|c|c|c|c|c|}
\hline & \multicolumn{2}{|c|}{ Sorted on debt-to-assets } & \multicolumn{2}{|c|}{ Sorted on market beta } \\
\hline & Low & High & Low & High \\
\hline & (1) & $(2)$ & $(3)$ & $(4)$ \\
\hline \multirow[t]{2}{*}{$\operatorname{logNumEst}$} & $0.016^{* *}$ & $0.018^{* * *}$ & $0.038^{* * *}$ & 0.004 \\
\hline & $(2.28)$ & $(2.60)$ & $(5.60)$ & $(0.57)$ \\
\hline \multirow[t]{2}{*}{ AnalyDisp } & $0.008^{*}$ & $0.015^{* * *}$ & $0.012^{* *}$ & $0.010^{* *}$ \\
\hline & $(1.87)$ & $(2.85)$ & $(2.37)$ & $(2.10)$ \\
\hline \multirow[t]{2}{*}{ Size } & $-0.014^{* * *}$ & -0.005 & $-0.018^{* * *}$ & $-0.019 * * *$ \\
\hline & $(-3.51)$ & $(-0.96)$ & $(-3.32)$ & $(-4.71)$ \\
\hline \multirow[t]{2}{*}{ Book-to-Market } & $-0.023^{* * *}$ & 0.000 & $-0.010^{* *}$ & -0.004 \\
\hline & $(-3.09)$ & $(0.24)$ & $(-2.23)$ & $(-1.33)$ \\
\hline \multirow[t]{2}{*}{ Momentum } & $-0.005 * * *$ & $-0.024^{* * *}$ & $-0.012^{* * *}$ & $-0.008^{* * *}$ \\
\hline & $(-3.72)$ & $(-7.35)$ & $(-4.30)$ & $(-5.14)$ \\
\hline \multirow[t]{2}{*}{ Intercept } & $0.255^{* * *}$ & $0.156^{* * *}$ & $0.165^{* * *}$ & $0.315^{* * *}$ \\
\hline & $(12.12)$ & $(5.39)$ & $(6.22)$ & $(14.13)$ \\
\hline Nobs & 131,172 & 131,020 & 133,094 & 132,954 \\
\hline Year-month f.e. & YES & YES & YES & YES \\
\hline Firm f.e. & YES & YES & YES & YES \\
\hline $\mathrm{R}^{2}$ & 0.444 & 0.443 & 0.464 & 0.426 \\
\hline Nfirms & 2607 & 2472 & 3569 & 3109 \\
\hline
\end{tabular}

The dependent variable in all regressions is monthly $A P A R C H \gamma$, our measure of volatility asymmetry developed in Section 3. Our main explanatory variable, $\log N u m E s t$, is the natural logarithm of the number of analysts following the stock in a given month according to IBES and proxies for the level of attention toward each stock. AnalyDisp is the dispersion of analyst forecasts of next quarter's earnings and is a common measure for differences of opinion. We sort stocks into terciles based on two previously suggested measures of leverage. In columns (1) and (2), we use the Debt - to - Assets ratio, defined as debt (long term + debt in current liabilities) divided by the sum of debt and market value of equity, which we obtain from quarterly accounting data in Compustat. In columns (3) and (4), we use annual market Beta of each stock, estimated at the end of each year following Scholes \& Williams (1977), which we obtain from CRSP. We then run regressions following Equation 6 in the bottom and top tercile separately and present the results. All variables are defined in Table 1. Monthly observations between 1989 and 2007 are used. $t$-statistics are calculated from standard errors clustered by stock. Significance levels: * $-0.1,{ }^{* *}-0.05, * * *-0.01$ 